Cite as: Janacsek, K., \& Nemeth, D. (2012). Predicting the future: from implicit learning to consolidation. International Journal of Psychophysiology, 83(2), 213-221.

\title{
Predicting the future: from implicit learning to consolidation
}

Karolina Janacsek \& Dezso Nemeth

Institute of Psychology, University of Szeged, Szeged, Hungary

The authors report no conflict of interest and have no financial disclosure.

Corresponding author: Dezso Nemeth, Ph.D., Institute of Psychology, University of Szeged, Hungary, Egyetem u. 2., 6722, Szeged, HUNGARY, Email: nemethd@edpsy.u-szeged.hu Web: http://www.memory-and-language.com/ , Phone: +36 62544 692, +36 62544 509, Fax: $+3662544509$ 


\begin{abstract}
Sequence learning can be differentiated according to phases (rapid and slower), modalities (perceptual and motor), and whether or not it is conscious (implicit and explicit). Implicit sequence learning occurs when information is acquired from an environment of complex stimuli without conscious access either to what was learned or to the fact that learning occurred. In everyday life, this learning mechanism is crucial for adapting to the environment and for predicting events unconsciously. Implicit sequence learning underlies not only motor, but also cognitive and social skills; it is therefore an important aspect of life from infancy to old age. Moreover, this kind of learning does not occur only during practice, in the so-called online periods, but also between practice periods, during the so-called offline periods. The process that occurs during the offline periods is referred to as consolidation, which denotes the stabilization of a memory trace after the initial acquisition; this can result in increased resistance to interference or even improvement in performance following an offline period. Understanding the multiple aspects and influencing factors of consolidation can help us to reveal the nature of memory and changes in brain plasticity. Our review focuses on how consolidation varies with factors such as awareness, the length of offline periods, the type of information to be learned, and the age of participants. We highlight that consolidation is not a single process; instead, there are multiple mechanisms in the offline period, which are differently influenced by these factors.
\end{abstract}

Keywords: implicit sequence learning, memory consolidation, sleep, offline changes, implicit predictions, aging, awareness, perceptual-motor learning 


\section{Introduction}

Prediction is one of the most fundamental functions of the brain. During every moment of our waking life, the brain is trying to anticipate future sensations. In order to recognize time-based patterns and predict subsequent events, storing and recalling of sequences are required (Hawkins et al., 2009). Without these skills, it would be impossible to carry out evolutionary adaptive behaviors. Most predictions are based on the implicit learning that occurs when information is acquired from an environment of complex stimuli, without conscious access either to what was learned or to the fact that learning occurred (Cleeremans et al., 1998; Reber, 1993). Despite the growing interest in implicit learning in the past decades, there has been relatively little research on offline processing of implicitly learned information (i.e., consolidation). Here, we review recent work on implicit sequence learning and its consolidation, with an emphasis on the last 10 years. More selectively, we address four of the most important factors that influence the consolidation of this fundamental learning mechanism. These factors must be taken into consideration before planning and performing brain imaging, psychophysiological, and behavioral studies on sequence learning and its consolidation.

Implicit sequence learning underlies not only motor, but also cognitive and social skills (Kaufman et al., 2010; Lieberman, 2000; Nemeth et al., 2011; Romano Bergstrom et al., 2011; Ullman, 2004); it is therefore an important aspect of life from infancy to old age. Implicit sequence learning is essential for learning languages, as well as learning to operate appliances, computer applications or musical instruments (Howard et al., 2004; Romano et al., 2010). Social skills appear in compound behaviors (including series of perceptions, emotions as well as motor actions) realized in proper sequences and under appropriate circumstances. These skills-for example, dialogues, decision making in social context, communication of emotions, predicting others' behavior based on previous verbal and nonverbal social 
communication, and adjusting our own behavior based on these predictions - are needed for normal social functioning in various sorts of situations: in the workplace, in the family, in the neighborhood, during recreation, shopping, or in the context of medical and mental care (Heerey and Velani, 2010; Lieberman, 2000; Nemeth and Janacsek, 2011). Furthermore, these skills are crucial for effective participation in educational, training, and rehabilitation programs, for instance in relearning how to walk, reach for objects, and speak after brain injury (Howard et al., 2004; Nemeth et al., 2010a).

Most models and empirical studies of skill learning highlight the role of the basal ganglia and the cerebellum (Dennis and Cabeza, 2010; Doyon et al., 2009a; Hikosaka et al., 1999; Hikosaka et al., 2002b; Keele et al., 2003; Kincses et al., 2008; Rieckmann et al., 2010; Sefcsik et al., 2009); in contrast, the role of the hippocampus remains inconclusive (Albouy et al., 2008; Schendan et al., 2003). A major approach to this research is through brain imaging and neuropsychological studies; in addition to these, experiments investigating the effects of pharmacological agents provide an opportunity for the better understanding of the biological background of implicit learning (for review see Uddén et al., 2010). For example, a study by Frank et al. (2006) showed that the benzodiazepine midazolam, which inactivates the hippocampus, causes explicit memory deficits in healthy participants, but enhances implicit learning. In contrast, a more recent study found impaired implicit learning after the exogenous administration of the stress hormone cortisol (Römer et al., 2011). The engagement of specific brain structures in these phenomena needs to be clarified.

In experimental settings, implicit learning is defined as the acquisition of cooccurrence/dependencies between stimuli or trials, and is expressed only through performance (Frensch, 1998; Howard et al., 2004; Rieckmann and Bäckman, 2009). In the past decades, several tasks have been developed to tap into implicit learning. These tasks can be organized into two main groups based on whether the covariation or the temporal sequence of stimuli 
has predictive information. For example, in artificial grammar learning, participants are exposed to strings of letters. They are not informed that the strings follow a set of rules; yet, it has been found that they can apply these rules at a later stage of practice (Dienes et al., 1991; Reber, 1989). In the weather prediction task, individuals have to decide whether a specific combination of cards predicts rainy or sunny weather. They are unaware that each combination of cards is probabilistically related to a particular weather outcome. During the task, participants learn gradually which of two outcomes will occur, although they have no conscious knowledge of the rule (Gluck et al., 2002; Kemény and Lukács, 2009; Kincses et al., 2004; Poldrack and Rodriguez, 2004). Similarly, in the contextual cueing task, the global configuration of a display cues the location of a search target (Chun and Jiang, 1998; Howard et al., 2006).

In these tasks, the covariation of certain stimuli (e.g., in a letter string/a set of cards) has predictive information, in contrast to sequence learning tasks, where participants have to predict the onset of a stimulus based on the preceding stimuli (Rieckmann and Bäckman, 2009). Evidence suggests that the latter type of task has partly different underlying mechanisms and activates partly different brain structures (Greene et al., 2007; Jimenez and Vázquez, 2011; Poldrack et al., 2005); therefore, it is important to differentiate between these two types of tasks. In recent years, a growing body of data has emerged regarding the consolidation of implicit sequence learning, while covariation learning has received less attention. In our review, we focus on the perceptual-motor learning of sequences. First, we describe the sequence learning tasks in more details. We follow this with a discussion of the consolidation processes and its potentially influencing factors. Finally, we consider developing questions and future directions on this research field. 


\section{Measures of implicit sequence learning}

A widely used sequence learning task is the finger tapping task (Figure 1A). Here, participants are instructed to produce a particular sequence of finger movements either on a response box or by opposing their fingers to their thumb (Doyon et al., 2002; Karni et al., 1995). Performance is measured by the number of correctly produced sequences over a certain time interval (e.g., $30 \mathrm{sec}$ ). Similarly to the previously mentioned tasks, participants' performance becomes better with practice. The main problem with this task is that it can be difficult to classify as truly implicit, because participants are aware of the sequence they have to generate. However, it is based on the learning of sequences and the learning is expressed through performance; therefore, we discuss the results based on this task where it is relevant to the question of consolidation.

In the past decade, the serial reaction time (SRT) task (Nissen and Bullemer, 1987) and its modification, the alternating serial reaction time (ASRT) task (Howard and Howard, 1997; Nemeth et al., 2010b), have become the most popular implicit sequence learning tasks. In the original version of the SRT task, a stimulus appears at one of four possible locations on the screen, and subjects have to press the button corresponding to that location (Figure 1A). They are unaware that the sequence of subsequent locations (and correspondingly, the sequence of the responses) follows a predetermined order (Hallgató et al., in press). For example, in classical SRT tasks, the structure of the sequence is deterministic, with the stimuli following a simple repeating pattern as in the series 213412431423 , where the numbers refer to distinct events (Figure 1B). Without becoming aware of the sequence, subjects learn the regularity - and as they learn, they produce faster and more accurate responses. When the sequence is changed to a random series of stimuli, subjects become slower and less accurate 
in responding. In this task, sequence learning is measured by the reaction time difference between sequence and random blocks.

The modified version of SRT is the alternating serial reaction time (ASRT) task (Howard and Howard, 1997; Nemeth et al., 2010b). Here, repeating events alternate with random ones in an eight-element sequence so that the location of every second stimulus in the stream is determined randomly. If, for instance, the sequence is 3214 , where the numbers represent locations on the screen, the sequence of the stimuli will be $3 R 2 R 1 R 4 R$, with $R$ representing a random element. The sequence is thus better hidden than in the classical SRT task. This structure is referred to as a probabilistic second-order dependency (Remillard, 2008). The structure is second-order in that for pattern trials, event $n$ - 2 predicts event $n$. It is probabilistic in that these pattern trials occur amid randomly determined ones. In addition, participants do not generally become aware of the alternating structure of the sequences, even after extended practice, and sensitive recognition tests indicate that people do not develop explicit knowledge of the event sequences that are more likely to occur (Howard et al., 2004; Howard and Howard, 1997; Song et al., 2007).

Because sequence, and random stimuli alternate in the ASRT task, some sequences of three events (called "triplets") occur more frequently than others (Figure 1B). In this task we can separate general skill learning from sequence-specific learning, where general skill learning refers to increasing speed as the result of practice. In contrast, sequence-specific learning refers to the acquisition of sequence-specific knowledge, resulting in relatively faster responses for more predictable high-frequency events compared to less predictable lowfrequency events. In the classical SRT task, sequence learning is measured as the RT difference between sequence and random blocks (Figure 1C). However, in this difference score, sequence-specific and general skill learning are mixed, because participants also exhibit general skill improvement on sequential blocks. Thus, the bigger difference between these 
two types of blocks could be attributed to sequence-specific and general skill learning together, and we cannot determine the extent of these two types of learning. ASRT allows these types of learning to be separated. Another advantage of the ASRT task compared to the classical SRT task is that in the ASRT, it is possible to track sequence-specific learning continuously by comparing responses to the random and sequence elements or more and less predictable events in all blocks. In summary, recent research favors the ASRT task, because 1) it is more implicit, 2) it can separate sequence-specific and general skill learning, and 3) it can continuously track these two types of learning across all blocks. 


\section{A) Task types}

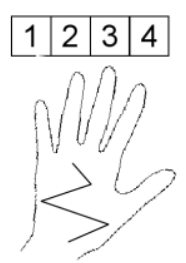

Finger tapping task

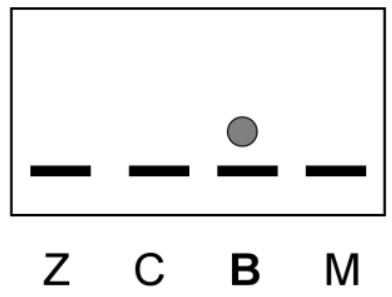

SRT/ASRT task
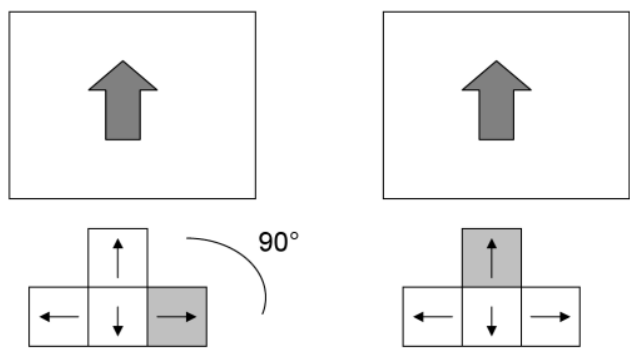

ASRT Race task - Learning and Transfer phase

\section{B) Sequence types}

Deterministic:

Probabilistic:

e.g., $2 r 3 r 1 r 4 r$ (in ASRT)

\begin{tabular}{|c|c|c|}
\hline & $\begin{array}{c}\text { High-frequency } \\
\text { triplets }\end{array}$ & $\begin{array}{c}\text { Low-frequency } \\
\text { triplets }\end{array}$ \\
\hline $\mathbf{1 - r}-\mathbf{2}$ & e.g., $1-4-2$ & (always high) \\
\hline $\mathbf{r}-\mathbf{4 - r}$ & e.g., $\mathbf{1 - 4 - 2}$ & e.g., $1-4-3$ \\
\hline
\end{tabular}

\section{C) Measuring the performance}

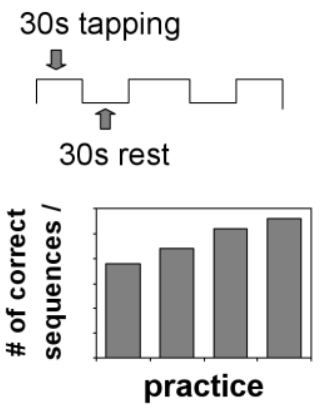

Finger tapping task

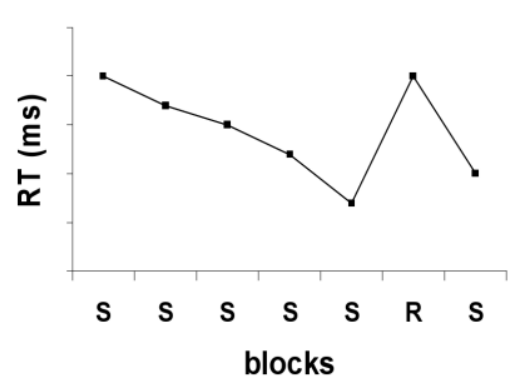

SRT task

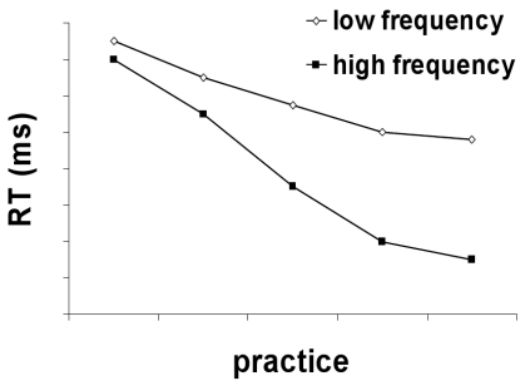

ASRT task

Figure 1. A) Examples of the most commonly used sequence learning paradigms. B) The main distinction in the case of sequence type is whether it is deterministic or probabilistic. C) Typical examples of performance measures in different sequence learning paradigms. In the finger tapping task, performance is measured by the number of correctly produced sequences over a certain time interval (e.g., $30 \mathrm{sec}$ ). In the classical SRT task, sequence learning is measured as the RT difference between sequence $(\mathrm{S})$ and random $(\mathrm{R})$ blocks. In the probabilistic sequence learning tasks (e.g., the ASRT task), sequence-specific learning is measured by comparing responses to the random and sequence elements or more and less predictable events in all blocks. 


\section{Consolidation of sequence knowledge}

Sequence learning does not occur only during practice, in the so-called online periods, but also between practice periods, during the so-called offline periods. The process that occurs during the offline periods is referred to as consolidation, which denotes the stabilization of a memory trace after the initial acquisition; this can result increased resistance to interference or even improvement in performance following an offline period (Krakauer and Shadmehr, 2006; Nemeth et al., 2010b; Robertson, 2009; Song, 2009).

This review will focus on factors that can determine the post-encoding stabilization and enhancement phases of consolidation. The consolidation can include the integration of recently acquired information with past experiences (memory association), the anatomical reorganization of memory representations (memory translocation), reconsolidation of memory representations after recall (memory reconsolidation), and even the erasure of memory representations, all of which appear to occur outside of awareness and without additional training. These processes can be time dependent or sleep dependent (Stickgold et al., 2002; Walker et al., 2003b; Walker and Stickgold, 2004). Hence, it is essential to differentiate between time-dependent and sleep-dependent consolidation. Time-dependent consolidation reflects the stabilization or even improvement of the memory trace after an offline period, irrespective of whether sleep occurred in this period or not. Thus, in this type of consolidation, sleep is not an essential component.

In recent decades, special attention has been given to the role of sleep; for instance references are made to sleep-dependent consolidation (Walker and Stickgold, 2004) suggesting that performance improves more when the offline period includes sleep than when it does not. Several studies have shown the critical role of sleep in skill learning consolidation (Fischer et al., 2002; Maquet et al., 2000; Peigneux et al., 2003; Stickgold et al., 2002; Walker 
et al., 2002). Nonetheless, the results concerning consolidation of sequence knowledge have been mixed, and recent findings indicate that whether or not offline improvements occur at all, and whether they are sleep dependent, varies with factors such as awareness, the length of the offline period, the type of information to be learned, and the age of the participants (Hallgató et al., in press; Nemeth and Janacsek, 2011; Press et al., 2005; Robertson et al., 2004; Song et al., 2007; Spencer et al., 2007).

Although a growing body of research and fertile models advance our understanding of online learning (e.g., Cohen and Squire, 1980; Hawkins et al., 2009; Henke, 2010; Willingham, 1997), less is known about the offline processes, and there are yet unresolved contradictions between some of the related findings. Therefore, it is critical to determine which factors can potentially influence the consolidation of sequence learning. We discuss four factors that must be taken into account in consolidation research: 1) The role of awareness, 2) the length of the offline period, 3) perceptual and motor sequences, and 4) the effect of age. Considering these factors, we can organize the findings that emerge more appropriately and build more effective models of consolidation.

\subsection{The role of awareness in consolidation}

Ample research using the finger tapping task suggests that sleep plays an important role in the consolidation of sequence learning (Doyon et al., 2009b; Fischer et al., 2002; Korman et al., 2003; Walker et al., 2003b; Walker and Stickgold, 2004). Walker et al. (2003b), for example, found that finger tapping skill developed to the highest degree during the first night of sleep following training, but additional nights of sleep also offered continued improvements. Other studies have suggested that sleep-dependent improvement is independent of whether sleep occurs during daytime or nighttime; even a 90-minute daytime 
nap, immediately after learning, resulted in robust gains (Fischer et al., 2002; Korman et al., 2007). Korman et al. (2003) found that time in sleep determined the time of expression of these delayed gains.

Regarding the consolidation-related neural mechanisms, Fischer et al. (2005) showed that sleep-dependent improvement was linked to greatly reduced brain activation in the prefrontal, premotor, and primary motor cortical areas, along with a stronger involvement of the left parietal cortical regions. Investigating the electroencephalographic characteristics of post-training sleep, Morin et al. (2008) found an increased number and duration of sleep spindles during the offline consolidation of sequential finger movements.

Using the SRT task, Robertson et al. (2004) found offline improvement after sleep as well, but only if participants gained declarative knowledge about the sequence. Robertson (2009) argued that the consolidation of explicit and implicit learning is differentially affected by sleep and wakefulness. In another study, Fischer et al. (2007) suggested that sleep leads to offline enhancement by increasing the explicit knowledge about the learned information. Hence, when participants are aware of the sequential structure, we can observe sleepdependent offline improvement (as in the studies using finger tapping or explicit SRT tasks). In some cases, however, this overnight enhancement in explicit knowledge can interfere with performance - for example, when the learning is implicit (Brown and Robertson, 2007; Galea et al., 2010) - even resulting in an overnight decrease of implicit knowledge (e.g., Fischer et al., 2007).

According to Robertson (2009), in implicit learning when there is no declarative knowledge about the task, consolidation may occur during both wakefulness and sleep. In line with this prediction, recent SRT and ASRT studies found similar consolidation of implicit sequence learning during both sleep and wakefulness (Nemeth et al., 2010b; Robertson et al., 2004; Song et al., 2007). For instance, Song et al. (2007) studied offline learning in young 
adults with the ASRT task, which has proven to be the most implicit sequence learning task because of its probabilistic properties (Howard et al., 2004). Participants were tested in three sessions, with an equivalent period of wake or sleep between sessions. There was no evidence of offline improvement in sequence-specific learning following either a period of sleep or wakefulness. The performance in the testing session, however, was the same as in the learning phase, suggesting that the sequential knowledge was well consolidated. Nemeth et al. (2010b) found similar results in elderly participants with the same method.

Summarizing these findings, when participants are aware of the sequence structure, offline improvement can occur only after sleep (for detailed explanation see Robertson, 2009). This claim is also in accordance with results from finger tapping tasks (Fischer et al., 2002; Walker et al., 2003b; Walker and Stickgold, 2004) and explicit SRT tasks (Robertson et al., 2004), because in those cases participants are aware of the sequence knowledge. In contrast, consolidation of implicit learning is independent of sleep. Thus, awareness of the sequential structure can modify the process of consolidation: When people gain explicit knowledge about the task, sleep-dependent consolidation occurs, while in the case of implicit learning, consolidation is only time dependent. Yet, it is important to note that there are other factors that may influence the effect of sleep in these tasks. For example, in finger tapping tasks, sequences are shorter and deterministic. In contrast, SRT tasks usually consist of longer deterministic sequences, while in ASRT tasks the sequences are probabilistic. Thus, the consolidation of implicit sequence knowledge might also depend on the type, length, and complexity of sequences. Nevertheless, to our knowledge, no study has comprehensively controlled and manipulated these factors.

We can interpret the role of awareness more deeply if we take into consideration that sleep affects evolutionarily newer brain structures, such as the frontal lobe, compared to other brain structures (Hobson, 2009; Muzur et al., 2002). Studies on the relationship between 
cognitive functions and normal or disrupted sleep suggest that sleep has a greater impact on cognitive functions connected to the frontal lobe and other cortical structures than on those connected to subcortical structures (Bearpark et al., 1987; Bedard et al., 1993; Bedard et al., 1991; Cosentino et al., 2000; Engelman et al., 2000; Gosselin et al., 2006; Hoekema et al., 2007; Naegele et al., 2006; Nemeth et al., in press; Nemeth et al., 2010b; Pierobon et al., 2008; Robertson et al., 2004; Song et al., 2007). Furthermore, the awareness of sequential structure can be related to cortical structures, primarily to the frontal lobe (Gomez Beldarrain et al., 2008; Gomez Beldarrain et al., 2002; Squire et al., 1993; Squire et al., 1990). These claims can explain the findings that in finger tapping and explicit SRT tasks, sleep-dependent consolidation can be obtained, in contrast to ASRT studies where participants gain no explicit knowledge about the task. Consequently, we can conclude that implicit learning connected to subcortical structures does not benefit from sleep.

\subsection{The length of the offline period}

The previously mentioned studies used a 12- or 24-hour delay between sessions to specifically investigate the role of sleep. However, another important question is what happens during consolidation in a much shorter or a much longer time interval. Studies on the time course of skill consolidation indicate that there is a "critical period" after the learning phase that is necessary for the stabilization of memory traces (Nemeth and Janacsek, 2011). This time period depends on the task demand, and it varies from 1-2 hours (Robertson et al., 2005) to 5 hours (Shadmehr and Brashers-Krug, 1997; Shadmehr and Holcomb, 1997) or 6 hours (Walker et al., 2003a). Before this time interval passes (e.g., immediately or $30 \mathrm{~min}$ after the learning session), the newly acquired skill is more sensitive to interference effects and no offline improvement is observed compared to longer delays. For example, using the 
SRT task, one study found that the gain of consolidation increased with the length of delay (Press et al., 2005). In this SRT study, no enhancement was found 1 hour after the learning phase, but significant enhancement was observed after 4 hours, and this further increased after 12 hours. These results suggest that offline learning may be a dynamic process. However, these studies examined only a shorter stretch of time, so the question remains of what happens in consolidation after more than 12 hours.

A recent ASRT study investigated the time course of implicit sequence learning by comparing the performance after 12-, 24-hour, and 1-week delays from the initial learning session (Nemeth and Janacsek, 2011). The researchers focused on the consolidation of implicit sequence-specific learning, and separately, general skill learning between young and elderly adults. The aim of the study was to determine a time point in a longer stretch of time at which improvement can still be observed in consolidation, and analyze its possible agerelated differences. In the young adults, the researchers found offline improvement of the general skill after all three delay periods, with a gradual decline among delays. Although no offline improvement was found in sequence-specific learning with any of the consolidation intervals, it did not decrease significantly between sessions for young participants, suggesting that sequence-specific knowledge consolidated well. Thus, according to these results, offline general skill learning is influenced by the time course. In contrast, offline sequence-specific learning is not affected by the length of the offline period, since the consolidation of sequential knowledge had already occurred after a 12-hour delay, and did not differ from the 24-hour and 1-week delay conditions.

These results are congruent with recent theories of consolidation (Press et al., 2005; Robertson et al., 2005; Shadmehr and Brashers-Krug, 1997; Shadmehr and Holcomb, 1997; Walker et al., 2003a), which claim that memory stabilization occurs during the first 5-6 hours after learning. The strong offline improvement of general skill that was observed after 12 
hours may reflect this first stabilization process of memory traces, including the previously mentioned critical time period (Nemeth and Janacsek, 2011). In addition, consolidation of sequence-specific information was similar in the 12-, 24-hour, and 1-week offline periods, independently of time course. These results suggest that the stabilization of sequence-specific memory is a faster process, because it had already occurred after 12 hours and did not differ from the other delay conditions. In contrast, in the case of general skill learning, further changes were observed after longer time intervals (e.g., 24-hour and 1-week delays) compared to the 12-hour delay condition (Nemeth and Janacsek, 2011). In another recent study, retention of the sequence-specific knowledge was found after a full year (Romano et al., 2010), suggesting that sequence knowledge without further practice is stable even after much longer periods.

\subsection{Perceptual and motor factors of sequence learning}

Another major debate in the field of sequence learning is whether we rely on "our hands" or on "our eyes" during learning (Deroost and Soetens, 2006; Keele et al., 2003; Kemény and Lukács, 2011; Mayr, 1996; Nemeth et al., 2009; Song et al., 2008; Ziessler and Nattkemper, 2001). In the classical sequence learning paradigms, such as the SRT and ASRT tasks, exactly what the participants learn is not clear: They might learn the sequence of the stimuli (perceptual learning), the sequence of their own eye movements (oculomotor learning), the sequence of response locations (response-based learning), or the sequence of given finger movements (effector-based learning) (Cohen et al., 1990; Remillard, 2003; Willingham, 1999). These factors determine not only the online learning process, but also the consolidation of sequence knowledge. 
In an SRT study, Willingham (1999) used two conditions to examine the perceptual and the motor factors of learning. In one condition, the stimulus-response mapping was changed in the transfer (test) phase that followed the learning phase, so that half of the participants had to press the same sequence of keys as in the learning phase but saw new stimuli (motor condition), whereas the other half had to press a different sequence of keys as in the learning phase but saw the same stimuli as before (perceptual condition). Willingham (1999) found that transfer was shown only when the motor sequence was kept constant, and not when the perceptual sequence was constant. In a previous study, Nemeth et al. (2009) compared the magnitude of perceptual and motor components of implicit sequence learning using a modification of the ASRT-task in a similar design.

In the ASRT-Race task, the stimuli were the left, right, up, and down arrows, which appeared in the center of the screen (minimizing oculomotor movements). In the learning phase, participants had to mentally rotate the arrows by 90 degrees to the right, and press the button corresponding to this rotated arrow. In the transfer phase, the stimulus-response mapping changed and participants no longer had to rotate the arrows (rather, they had to press the left button when seeing the left arrow). Half of the participants were assigned to the perceptual and the other half to the motor condition. In the perceptual condition, the perceptual sequence was the same, but the motor sequence (key presses) changed compared to the previously practiced sequence. Conversely, key presses followed the previously learned sequence and the perceptual information (the sequence of the stimuli displayed on the screen) changed in the motor condition. The goal of comparing the participants' performance between these two conditions was to determine whether the contribution of perceptual and motor component was the same as or different from the learning (for more details see Nemeth et al., 2009). This task involves second-order probabilistic sequences, whereas classical SRT tasks use deterministic sequences. ASRT-Race also allows "pure" sequence learning to be 
measured separately from general skill improvements, where sequence learning is reflected in the difference between the reaction times to more as opposed to less predictable events. In addition, this task eliminates the possibility of oculomotor learning, as stimuli always appear in the same central position on the screen. In contrast to Willingham's findings, Nemeth et al. (2009) demonstrated that not only motor, but also perceptual learning of second-order probabilistic sequences is possible. Furthermore, Nemeth et al. (2009) showed that the two types of learning do not differ significantly in magnitude.

Although several studies have investigated the perceptual and motor components of online sequence learning (Deroost and Soetens, 2006; Mayr, 1996; Nemeth et al., 2009; Remillard, 2003, 2009; Song et al., 2008), to our knowledge, the effect of consolidation on the perceptual and motor characteristics of learning has received less empirical attention. The goal of the Hallgató et al.'s (in press) study was to fill this gap by investigating how the offline period modifies motor and perceptual components of implicit sequence learning. This issue is of particular interest because it deals with the question of whether sequence learning and consolidation are mediated primarily by perceptual or by motor brain networks (Deroost and Soetens, 2006; Goschke, 1998). Hallgató et al.'s study investigated the role of 12-hour and 24-hour delay on the perceptual and motor components of implicit sequence learning using the ASRT-Race task, while eliminating oculomotor learning. In addition, they aimed to explore the role of sleep in offline consolidation of these two factors of learning. Therefore, a 12-hour delay was administered between the learning phase and the transfer phase of the experiment, during which participants either slept (night group) or stayed awake (day group). They found significant sequence learning in the learning phase. Moreover, after the 12-hour and the 24-hour offline period, they found a significant learning effect in both the perceptual and the motor conditions; however, the transfer in the motor condition was more effective 
compared to the perceptual condition. They did not find any sleep effect on sequence learning in either condition.

The weaker consolidation of the perceptual component of sequence learning is in agreement with the results of Deroost and Soetens (2006) and Willingham (1999), who found evidence of perceptual learning only under specific conditions. According to several studies, perceptual learning only takes place when the structure of the sequence is simple, but in case of deterministic sequences with second-order dependencies and probabilistic sequences with first-order dependencies, perceptual learning is absent or only weakly present (Deroost and Soetens, 2006; Mayr, 1996; Remillard, 2003). In addition, previous studies found perceptual learning in explicit conditions (Russeler and Rosler, 2000) and when a motor sequence was learned concurrently (Mayr, 1996). In Hallgató et al.'s (in press) study, participants had no conscious awareness at all of the structure of the sequence. The only condition that met Deroost's (2006) criteria is that in the learning phase, participants learned the perceptual and motor components concurrently. Compared to Nemeth et al. (2009), who found similar magnitudes of perceptual and motor learning immediately after the learning phase, Hallgató et al. (in press) found a weaker perceptual learning effect in the transfer phase both after a 12hour and a 24-hour delay. As the only difference was the 12-hour or the 24-hour delay, Hallgató et al. supposed that the differences between the results of the two studies can be related to the consolidation period only. Thus, this criterion, where in the Learning Phase, participants learned the perceptual and motor components concurrently, can be enough to infer that significant perceptual learning occurs immediately after the learning phase (Meier and Cock, 2010; Nemeth et al., 2009; Weiermann et al., 2010). However, it might also result in weaker consolidation after the delay period. One potential explanation for this is that brain structures underlying the perceptual and motor components of sequence learning are disconnected in the offline periods, and the perceptual component might be more sensitive to 
interference effects. To put the puzzle together, we propose that the consolidation period has a differential effect on the motor and perceptual components of sequence learning, so that in the transfer phase, the motor component is larger than the perceptual one. However, more investigations are needed to determine the potential background mechanisms of this phenomenon.

Beyond the question of the perceptual and motor components of learning, Hallgató et al.'s study has relevance for the sleep debate in consolidation as well (Debas et al., in press; Doyon et al., 2009b; Gerván and Kovács, 2007; Karni, 1994; Robertson, 2009; Song, 2009; Stickgold and Walker, 2005; Walker et al., 2002). Hallgató et al. also found that sleep does not benefit sequence learning. In addition, the role of sleep in the consolidation of motor and perceptual factors of implicit sequence learning exhibits no difference. Another plausible explanation besides those previously mentioned (e.g., awareness, the separation of general skill and sequence-specific learning) is that in the probabilistic sequence learning task used in this study, in addition to the primary sensory and motor brain regions, the subcortical structures and cerebellum are more involved (Doyon, 2008; Hikosaka et al., 1999; Hikosaka et al., 2002a). This contrasts with the more basic finger tapping tasks, where sleep-dependent improvement has usually been found (Walker et al., 2002).

\subsection{The effect of aging on consolidation}

As implicit sequence learning is highly dependent on the integrity of the striatal network, and age-related structural and biochemical losses are pronounced in the striatal complex and connected prefrontal areas (Dennis and Cabeza, 2010; Raz et al., 2005; Rieckmann and Bäckman, 2009), how online and offline sequence learning is affected by aging is an important question. 
Several studies have shown that older adults exhibit online implicit sequence-specific learning comparable to young adults for simple repeating patterns in the SRT task (Brown et al., 2009; Fraser et al., 2009; Frensch and Miner, 1994; Howard and Howard, 1989; Howard and Howard, 1992). However, more recent studies have reported that although older adults can learn higher-order sequence structure, they show age-related deficits in doing so (Curran, 1997; Howard et al., 2004; Howard and Howard, 1997; Nemeth and Janacsek, 2011; Nemeth et al., 2010b). For example, using a version of the ASRT task, Bennett et al. (2007) found that old persons were able to learn even third-order dependencies (1RR2RR3 where R is a random element), although they learned less than the young control group.

Only a few studies have investigated the consolidation of implicit knowledge in older persons (Brown et al., 2009; Fraser et al., 2009; Nemeth and Janacsek, 2011; Nemeth et al., 2010b; Siengsukon and Boyd, 2009a, b; Spencer et al., 2007). Spencer et al. (2007), for example, used an implicit contextual version of the SRT task in order to specifically examine the effect of sleep. In a previous study, they found sleep-related offline improvement in this version of the task among young adults (probably because it's contextual component; Spencer et al., 2006). In older subjects, however, neither offline improvement nor a sleep effect was shown (Spencer et al., 2007). Compared to young adults, elderly participants showed deficits in consolidation. Similarly, Brown et al. (2009) found age-related consolidation deficits using the classical version of the SRT task. Nevertheless, neither Spencer et al. (2007) nor Brown et al. (2009) could distinguish general skill learning from sequence-specific learning in their tasks. As the ASRT task has been shown to yield offline general skill learning, but not offline sequence-specific learning in young adults (Song et al., 2007), it is important to differentially analyze these two aspects of implicit sequence learning in older adults as well.

Nemeth et al. (2010b) investigated implicit sequence learning after a 12-hour offline period. The novelty of this research in comparison to previous studies of consolidation in 
older adults (Brown et al., 2009; Siengsukon and Boyd, 2009a; Spencer et al., 2007) was that 1) it used probabilistic second-order sequences, and 2) it dealt separately with general skill and sequence-specific learning. The researchers showed that general skill learning improved offline in both the young and older groups, with the young group improving more than the old group. However, the improvement was not sleep dependent, in that it was not relevant whether the 12-hour offline period included sleep or not. In the case of sequence-specific learning, they found no offline improvement in either group.

A more recent study investigated the consolidation of implicit sequence learning by comparing the performance after 12-, 24-hour, and 1-week delays from the initial learning session in young and elderly adults (Nemeth and Janacsek, 2011). In the young adults, the researchers found offline improvement of the general skill after all delays, with gradual decline among them. The elderly adults showed offline improvement of the general skill only after the 12-hour offline period, and this improvement was weaker than that in the young group. Although the pattern in age groups is similar, these results suggest that the offline course of general skill learning may be affected by aging, since Nemeth and Janacsek did not find improvement either after a 24-hour or 1-week delay in the elderly group. No offline improvement was found in sequence-specific learning in either age group with any of the consolidation intervals. Sequence-specific learning did not decrease significantly between sessions for young participants, suggesting that sequence-specific knowledge was well consolidated in this group, whereas the older group showed weaker consolidation in all delay conditions compared to the younger group. Thus, according to these results, offline general skill learning is influenced both by the time course and aging, while the offline sequence learning is affected only by aging.

The differences between the young and old groups suggest that older participants are more sensitive to the time course in general skill learning, in that they showed no offline 
improvement even after the 24-hour delay. Regarding the practical consequences, the differences among the 12-, 24-hour, and 1-week consolidation intervals suggest that during new skill acquisition, it could be important to hold the training sessions closer together for optimal performance, with shorter intervals for elderly participants (Nemeth and Janacsek, 2011).

In the case of sequence-specific learning, older people show deficits both in online learning when the sequence structure is more complex and in the consolidation of sequence knowledge. A recent neuroimaging study (Dennis and Cabeza, 2010) found that elderly participants recruited medial temporal lobe structures in implicit sequence learning tasks, suggesting that compensation mechanisms are present to perform to an optimal level in these tasks. However, further studies are needed to precisely determine these compensation mechanisms and their potential role in age-related dementia and rehabilitation programs.

\section{Conclusion and remaining questions}

In view of the above, we can conclude that consolidation is not a single process; instead, there are multiple mechanisms in the offline period (e.g. general skill, sequencespecific processes), which are differently influenced by the task demand, awareness of the sequence, the length of the delay period, perceptual and motor factors, and the age of the participant (Table 1). Contradictions in this field can occur due to low or absent control of these factors of sequence learning. For example, sleep does not benefit sequence learning performance in the case of probabilistic sequences (Nemeth et al., 2010b; Song et al., 2007), because such sequences are more complex and implicit compared to simple and explicit sequence structures such as those used in finger tapping tasks. Consequently, the awareness of 
the sequence structure can modify the role of sleep in the consolidation process (Robertson, 2009; Robertson et al., 2004; Song, 2009).

The length of the delay period between the learning and testing phase is also an important factor that differentially modifies general skill and sequence-specific learning. In the case of general skill learning, the length of the delay is critical: The highest offline improvement is observed after shorter delay periods (Nemeth and Janacsek, 2011). In contrast, the delay period has less effect on sequence-specific learning: Retention of the previously acquired knowledge has been observed after one week (Nemeth and Janacsek, 2011) and even one year (Romano et al., 2010), but without additional offline improvement. Separating the perceptual and motor factors of learning can further elucidate this issue in that consolidation of motor sequence learning is more robust than perceptual factor of sequence learning. Nevertheless, more investigations are needed to replicate this finding and further detail its potential background mechanisms. Finally, one of the most important factors that must be taken into consideration is the age of participants, since several studies found significant age-related deficits in the consolidation of both sequence-specific and general skill learning in elderly adults (Brown et al., 2009; Nemeth and Janacsek, 2011). 
Table 1. Factors that influence consolidation of sequence learning and related studies.

\section{Factors}

Awareness (Explicit vs. implicit)

Length of delay period

Perceptual vs. motor

Age of participants

\section{Related studies}

Fischer et al. (2007); Fischer et al. (2002); Korman et al. (2007); Korman et al. (2003); Nemeth et al. (2010);

Robertson et al. (2004); Song et al. (2007); Walker et al. (2003b)

Nemeth and Janacsek (2011); Press et al. (2005);

Robertson et al. (2005); Romano et al. (2010); Shadmehr and Brashers-Krug (1997); Shadmehr and Holcomb (1997); Walker et al. (2003a)

Hallgató et al. (in press)

Brown et al. (2009); Fraser et al. (2009); Nemeth and Janacsek (2011); Nemeth et al. (2010); Spencer et al. (2007)

Further studies of sequence consolidation should take these factors into consideration and investigate the following issues: 1) How consolidation affects implicit sequence learning in childhood in the separate cases of general skill learning and sequence-specific learning; 2) whether there is differential consolidation of the perceptual and motor factors of sequence learning in older ages; 3) how the length of delay modifies the consolidation of explicit sequence knowledge in the case of general skill and sequence specific learning; and finally 4) whether the length of delay has a differential effect on perceptual and motor consolidation in the case of explicit sequence learning.

Ultimately, we know a lot about the biological background of online implicit sequence learning (Albouy et al., 2008; Dennis and Cabeza, 2010; Doyon et al., 2009a; Keele et al., 2003; Kincses et al., 2008; Poldrack et al., 2005; Rieckmann et al., 2010; Sefcsik et al., 2009). However, there is a huge gap in our knowledge related to brain plasticity during 
consolidation. Future neuroscientific investigations must address this question while controlling for the above-mentioned factors, especially the differentiation between general skill and sequence-specific learning. These distinctions can contribute to developing a more sophisticated picture of brain-consolidation-behavior interaction.

\section{Acknowledgement}

Thanks to Gabor Orosz for helpful comments on the manuscript. This review was supported by OTKA K 82068 (Hungarian Scientific Research Fund).

\section{References}

Albouy, G., Sterpenich, V., Balteau, E., Vandewalle, G., Desseilles, M., Dang-Vu, T., Darsaud, A., Ruby, P., Luppi, P.H., Degueldre, C., Peigneux, P., Luxen, A., Maquet, P., 2008. Both the hippocampus and striatum are involved in consolidation of motor sequence memory. Neuron 58, 261-272.

Bearpark, H., Grunstein, R., Touyz, S., Channon, L., Sullivan, C., 1987. Cognitive and psychological dysfunction in sleep apnea before and after treatment with CPAP. Journal of Sleep Research 16, 303-310.

Bedard, M.A., Montplaisir, J., Malo, J., Richer, F., Rouleau, I., 1993. Persistent neuropsychological deficits and vigilance impairment in sleep apnea syndrome after treatment with continuous positive airways pressure (CPAP). Journal of Clinical Experimental Neuropsychology 15, 330-341.

Bedard, M.A., Montplaisir, J., Richer, F., Rouleau, I., Malo, J., 1991. Obstructive sleep apnea syndrome: pathogenesis of neuropsychological deficits. Journal of Clinical Experimental Neuropsychology 13, 950-964. 
Bennett, I.J., Howard, J.H., Jr., Howard, D.V., 2007. Age-Related Differences in Implicit Learning of Subtle Third-Order Sequential Structure. Journal of Gerontology: Psychological Sciences 62B, 98-103.

Brown, R.M., Robertson, E.M., 2007. Off-line processing: reciprocal interactions between declarative and procedural memories. Journal of Neuroscience 27, 10468-10475.

Brown, R.M., Robertson, E.M., Press, D.Z., 2009. Sequence skill acquisition and off-line learning in normal aging. PloS one 4, e6683.

Chun, M.M., Jiang, Y., 1998. Contextual cueing: Implicit learning and memory of visual context guides spatial attention. Cognitive Psychology 36, 28.

Cleeremans, A., Destrebecqz, A., Boyer, M., 1998. Implicit learning: news from the front. Trends in Cognitive Sciences 2, 406-416.

Cohen, A., Ivry, R.I., Keele, S.W., 1990. Attention and structure in sequence learning. Journal of Experimental Psychology: Learning, Memory, and Cognition 16, 17-30.

Cohen, N.J., Squire, L.R., 1980. Preserved learning and retention of pattern-analyzing skills in amnesia: Dissociation of knowing how and knowing that. Science 210, 207-210.

Cosentino, F.I.I., Bosco, P., Drago, V., Prestianni, G., Lanuzza, B., Iero, I., Tripodi, M., Spada, R.S., Toscano, G., Caraci, F., Ferri, R., 2000. The APOE e4 allele increases the risk of impaired spatial working memory in obstructive sleep apnea. . Sleep Medicine 9, 831-839.

Curran, T., 1997. Effects of aging on implicit sequence learning: accounting for sequence structure and explicit knowledge. Psychological Research 60, 24-41.

Debas, K., Carrier, J., Orban, P., Barakat, M., Lungu, O., Vandewalle, G., Tahar, A.H., Bellec, P., Karni, A., Ungerleider, L.G., Benali, H., Doyon, J., in press. Brain plasticity related to the consolidation of motor sequence learning and motor adaptation. Proceedings of the National Academy of Sciences of the United States of America. 
Dennis, N., Cabeza, R., 2010. Age-related dedifferentiation of learning systems: an fMRI study of implicit and explicit learning. Neurobiology of Aging.

Deroost, N., Soetens, E., 2006. Perceptual or motor learning in SRT tasks with complex sequence structures. Psychol Res 70, 88-102.

Dienes, Z., Broadbent, D., Berry, D., 1991. Implicit and explicit knowledge bases in artificial grammar learning. Journal of Experimental Psychology: Learning, Memory, and Cognition $17,875-887$.

Doyon, J., 2008. Motor sequence learning and movement disorders. Curr Opin Neurol 21, 478-483.

Doyon, J., Bellec, P., Amsel, R., Penhune, V., Monchi, O., Carrier, J., Lehericy, S., Benali, H., 2009a. Contributions of the basal ganglia and functionally related brain structures to motor learning. Behav Brain Res 199, 61-75.

Doyon, J., Korman, M., Morin, A., Dostie, V., Hadj Tahar, A., Benali, H., Karni, A., Ungerleider, L.G., Carrier, J., 2009b. Contribution of night and day sleep vs. simple passage of time to the consolidation of motor sequence and visuomotor adaptation learning. Exp Brain Res 195, 15-26.

Doyon, J., Song, A.W., Karni, A., Lalonde, F., Adams, M.M., Ungerleider, L.G., 2002. Experience-dependent changes in cerebellar contributions to motor sequence learning. Proc Natl Acad Sci U S A 99, 1017-1022.

Engelman, H.M., Kingshott, R.N., Martin, S.E., Douglas, N.J., 2000. Cognitive function in the sleep apnea/hypopnea syndrome (SAHS). Sleep 23, 102-108.

Fischer, S., Fischer, S., Wilhelm, I., Born, J., 2007. Developmental differences in sleep's role for implicit off-line learning: Comparing children with adults. Journal of Cognitive Neuroscience 19, 214. 
Fischer, S., Hallschmid, M., Elsner, A.L., Born, J., 2002. Sleep forms memory for finger skills. PNAS 99, 11987-11991.

Fischer, S., Nitschke, M.F., Melchert, U.H., Erdmann, C., Born, J., 2005. Motor memory consolidation in sleep shapes more effective neuronal representations. The Journal of Neuroscience 25, 11248-11255.

Frank, M.J., O'Reilly, R.C., Curran, T., 2006. When Memory Fails, Intuition Reigns: Midazolam Enhances Implicit Inference in Humans. Psychological Science 17, 700 - 707.

Fraser, S.A., Li, K.Z.H., Penhune, V.B., 2009. A comparison of motor skill learning and retention in younger and older adults. Experimental Brain Research 195, 419-427.

Frensch, P.A., 1998. One concept, multiple meanings, in: Stadler, M.A., Frensch, P.A. (Eds.), Handbook of implicit learning. SAGE Publications, London, pp. 47-104.

Frensch, P.A., Miner, C.S., 1994. Effects of presentation rate and individual differences in short-term memory capacity on an indirect measure of serial learning. Memory and Cognition $22,95-110$.

Galea, J.M., Albert, N.B., Ditye, T., Miall, R.C., 2010. Disruption of the dorsolateral prefrontal cortex facilitates the consolidation of procedural skills. Journal of Cognitive Neuroscience 22, 1158-1164.

Gerván, P., Kovács, I., 2007. Sleep dependent learning in contour integration. Journal of Vision 7, 48 .

Gluck, M.A., Shohamy, D., Myers, C., 2002. How do people solve the "weather prediction" task?: individual variability in strategies for probabilistic category learning. Learn Mem 9, 408-418.

Gomez Beldarrain, M., Astorgano, A.G., Gonzalez, A.B., Garcia-Monco, J.C., 2008. Sleep improves sequential motor learning and performance in patients with prefrontal lobe lesions. Clinical Neurology and Neurosurgery 110, 245-252. 
Gomez Beldarrain, M., Gafman, J., Ruiz De Valesco, V., Pascual-Leone, A., Garcia-Monco, J.C., 2002. Prefrontal lesions impair the implicit and explicit learning of sequences on visuomotor tasks. Experimental brain research 142, 529-538.

Goschke, T., 1998. Implicit learning of perceptual and motor sequences: Evidence for independent learning systems, in: Stadler, M.A., Frensch, P.A. (Eds.), Handbook of implicit learning. SAGE Publications, London, pp. 401-444.

Gosselin, N., Mathieu, A., Mazza, S., Petit, D., Malo, J., Montplaisir, J., 2006. Attentional deficits in patients with obstructive sleep apnea syndrome: an event-related potential study. Clinical Neurophysiology 117, 2228-2235.

Greene, A.J., Gross, W.L., Elsinger, C.L., Rao, S.M., 2007. Hippocampal differentiation without recognition: An fMRI analysis of the contextual cueing task. Learning \& Memory 14, $548-553$

Hallgató, E., Gyori-Dani, D., Pekár, J., Janacsek, K., Nemeth, D., in press. The differential consolidation of perceptual and motor learning in skill acquisition. Cortex.

Hawkins, J., George, D., Niemasik, J., 2009. Sequence memory for prediction, inference and behaviour. Philosophical Transactions of the Royal Society B: Biological Sciences 364, 1203 1209.

Heerey, E.A., Velani, H., 2010. Implicit learning of social predictions. Journal of Experimental Social Psychology 46, 577-581.

Henke, K., 2010. A model for memory systems based on processing modes rather than consciousness. Nature Reviews Neuroscience 11, 523-532.

Hikosaka, O., Nakahara, H., Rand, M.K., Sakai, K., Lu, X., Nakamura, K., Miyachi, S., Doya, K., 1999. Parallel neural networks for learning sequential procedures. TINS 22, 464-471.

Hikosaka, O., Nakamura, K., Sakai, K., Nakahara, H., 2002a. Central mechanisms of motor skill learning. Current Opinion in Neurobiology 12, 217-222. 
Hikosaka, O., Nakamura, K., Sakai, K., Nakahara, H., 2002b. Central mechanisms of motor skill learning. Curr Opin Neurobiol 12, 217-222.

Hobson, J.A., 2009. REM sleep and dreaming: towards a theory of protoconsciousness. Nat Rev Neurosci 10, 803-813.

Hoekema, A., Stegenga, B., Bakker, M., Brouwer, W.H., de Bont, L.G., Wijkstra, P.J., van der Hoeven, J.H., 2007. Simulated driving in obstructive sleep apnoea-hypopnoea; effects of oral appliances and continuous positive airway pressure. Sleep Breath 11, 129-138.

Howard, D.V., Howard, J.H., 1992. Adult age differences in the rate of learning serial patterns: Evidence from direct and indirect tests. Psychology and Aging 7, 232-241.

Howard, D.V., Howard, J.H., Jr., 1989. Age differences in learning serial patterns: direct versus indirect measures. Psychology and Aging 4, 357-364.

Howard, D.V., Howard, J.H., Jr., Japikse, K., DiYanni, C., Thompson, A., Somberg, R., 2004. Implicit sequence learning: effects of level of structure, adult age, and extended practice. Psychology and Aging 19, 79-92.

Howard, J.H., Jr., Howard, D.V., 1997. Age differences in implicit learning of higher-order dependencies in serial patterns. Psychology and Aging 12, 634-656.

Howard, J.H., Jr., Howard, J.H., Jr., Howard, D.V., Japikse, K.C., Eden, G.F., 2006. Dyslexics are impaired on implicit higher-order sequence learning, but not on implicit spatial context learning. Neuropsychologia 44, 1131.

Jimenez, L., Vázquez, G.A., 2011. Implicit sequence learning and contextual cueing do not compete for central cognitive resources. Journal of Experimental Psychology: Human Perception and Performance 37, 222-235.

Karni, A., 1994. Dependence on Rem-sleep of overnight improvement of a perceptual skill. Science 265, 679-682. 
Karni, A., Meyer, G., Jezzard, P., Adams, M.M., Turner, R., Ungerleider, L.G., 1995. Functional MRI evidence for adult motor cortex plasticity during motor skill learning. Nature $377,155-158$.

Kaufman, S.B., DeYoung, C.G., Gray, J.R., Jiménez, L., Brown, J., Mackintosh, N., 2010. Implicit learning as an ability. Cognition 116, 321-340.

Keele, S.W., Ivry, R., Mayr, U., Hazeltine, E., Heuer, H., 2003. The cognitive and neural architecture of sequence representation. Psychological Review 110, 316-339.

Kemény, F., Lukács, Á., 2009. The effects of feature analysis, transparency in probabilistic category learning in adults and children. Learning \& Perception 1, 199-213.

Kemény, F., Lukács, Á., 2011. Perceptual Effect on Motor Learning in the Serial ReactionTime Task. The Journal of General Psychology 138, 110-126.

Kincses, T., Johansen-Berg, H., Tomassini, V., Bosnell, R., Matthews, P., Beckmann, C., 2008. Model-free characterization of brain functional networks for motor sequence learning using fMRI. Neuroimage 39, 1950-1958.

Kincses, T.Z., Antal, A., Nitsche, M.A., Bártfai, O., Paulus, W., 2004. Facilitation of probabilistic classification learning by transcranial direct current stimulation of the prefrontal cortex in the human. Neuropsychologia 42, 113-117.

Korman, M., Doyon, J., Doljansky, J., Carrier, J., Dagan, Y., Karni, A., 2007. Daytime sleep condenses the time course of motor memory consolidation. Nat Neurosci 10, 1206-1213.

Korman, M., Raz, N., Flash, T., Karni, A., 2003. Multiple shifts in the representation of a motor sequence during the acquisition of skilled performance. Proc Natl Acad Sci U S A 100, p12492-12497.

Krakauer, J.W., Shadmehr, R., 2006. Consolidation of motor memory. Trends Neurosci 29, 58-64. 
Lieberman, M.D., 2000. Intuition: a social cognitive neuroscience approach. Psychological Bulletin 126, 109-137.

Maquet, P., Laureys, S., Peigneux, P., Fuchs, S., Petiau, C., Phillips, C., Aerts, J., Del Fiore, G., Degueldre, C., Meulemans, T., Luxen, A., Franck, G., Van Der Linden, M., Smith, C., Cleeremans, A., 2000. Experience-dependent changes in cerebral activation during human REM sleep. Nature Neuroscience 3, 831-836.

Mayr, U., 1996. Spatial attention and implicit sequence learning: Evidence for independent learning of spatial and nonspatial sequences. Journal of Experimental Psychology 22, 350364.

Meier, B., Cock, J., 2010. Are correlated streams of information necessary for implicit sequence learning? Acta psychologica 133, 17-27.

Morin, A., Doyon, J., Dostie, V., Barakat, M., Hadj Tahar, A., Korman, M., Benali, H., Karni, A., Ungerleider, L.G., Carrier, J., 2008. Motor sequence learning increases sleep spindles and fast frequencies in post-training sleep. Sleep 31, 1149-1156.

Muzur, A., Pace-Schott, E.F., Hobson, J.A., 2002. The prefrontal cortex in sleep. Trends Cogn Sci 6, 475-481.

Naegele, B., Launois, S.H., Mazza, S., Feuerstein, C., Pepin, J.L., Levy, P., 2006. Which memory processes are affected in patients with obstructive sleep apnea? An evaluation of 3 types of memory. Sleep 29, 533-544.

Nemeth, D., Csábi, E., Janacsek, K., Várszegi, M., Mari, Z., in press. Intact implicit probabilistic sequence learning in Obstructive Sleep Apnea. Sleep Medicine.

Nemeth, D., Hallgato, E., Janacsek, K., Sandor, T., Londe, Z., 2009. Perceptual and motor factors of implicit skill learning. Neuroreport 20, 1654-1658.

Nemeth, D., Janacsek, K., 2011. The dynamics of implicit skill consolidation in young and elderly adults. Journal of Gerontology Psychological Science 66, 15-22. 
Nemeth, D., Janacsek, K., Balogh, V., Londe, Z., Mingesz, R., Fazekas, M., Jambori, S., Danyi, I., Vetro, A., 2010a. Learning in Autism: Implicitly Superb. PloS ONE 5, e11731.

Nemeth, D., Janacsek, K., Csifcsak, G., Szvoboda, G., Howard, J.H., Jr., Howard, D.V., 2011. Interference between Sentence Processing and Probabilistic Implicit Sequence Learning. PloS one 6 , e17577.

Nemeth, D., Janacsek, K., Londe, Z., Ullman, M.T., Howard, D., Howard, J., 2010b. Sleep has no critical role in implicit motor sequence learning in young and old adults. Experimental Brain Research 201, 351-358.

Nissen, M.J., Bullemer, P., 1987. Attentional requirements of learning: Evidence from performance measures. Cognitive Psychology 19, 1-32.

Peigneux, P., Laureys, S., Fuchs, S., Destrebecqz, A., Collette, F., Delbeuck, X., Phillips, C., Aerts, J., Del Fiore, G., Degueldre, C., Luxen, A., Cleeremans, A., Maquet, P., 2003. Learned material content and acquisition level modulate cerebral reactivation during posttraining rapid-eye-movements sleep [In Process Citation]. NeuroImage 20, 125-134.

Pierobon, A., Giardini, A., Fanfulla, F., Callegari, S., Majani, G., 2008. A multidimensional assessment of obese patients with obstructive sleep apnoea syndrome (OSAS): a study of psychological, neuropsychological and clinical relationships in a disabling multifaceted disease. Sleep Medicine 9, 882-889.

Poldrack, R.A., Rodriguez, P., 2004. How do memory systems interact? Evidence from human classification learning. Neurobiol Learn Mem 82, 324-332.

Poldrack, R.A., Sabb, F.W., Foerde, K., Tom, S.M., Asarnow, R.F., Bookheimer, S.Y., Knowlton, B.J., 2005. The Neural Correlates of Motor Skill Automaticity. Journal of Neuroscience 25, 5356 - 5364.

Press, D.Z., Casement, M.D., Pascual-Leone, A., Robertson, E.M., 2005. The time course of off-line motor sequence learning. Brain Res Cogn Brain Res 25, 375-378. 
Raz, N., Lindenberger, U., Rodrigue, K.M., Kennedy, K.M., Head, D., Williamson, A., Dahle, C., Gerstorf, D., Acker, J.D., 2005. Regional brain changes in aging healthy adults: general trends, individual differences and modifiers. Cereb Cortex 15, 1676-1689.

Reber, A.R., 1993. Implicit learning and tacit knowledge: An essay on the cognitive unconscious. Oxford University Press, New York.

Reber, A.S., 1989. Implicit learning and tacit knowledge. Journal of Experimental Knowledge $118,219-235$.

Remillard, G., 2003. Pure perceptual-based sequence learning. Journal of Experimental Psychology: Learning, Memory, and Cognition 29, 581-597.

Remillard, G., 2008. Implicit learning of second-, third-, and fourth-order adjacent and nonadjacent sequential dependencies. The Quarterly Journal of Experimental Psychology 61, 400-424.

Remillard, G., 2009. Pure perceptual-based sequence learning: A role for visuospatial attention. Journal of Experimental Psychology: Learning, Memory, and Cognition 35, 528.

Rieckmann, A., Bäckman, L., 2009. Implicit learning in aging: Extant patterns and new directions. Neuropsychology review 19, 490-503.

Rieckmann, A., Fischer, H., Bäckman, L., 2010. Activation in striatum and medial temporal lobe during sequence learning in younger and older adults: Relations to performance. Neuroimage 50, 1303-1312.

Robertson, E.M., 2009. From creation to consolidation: A novel framework for memory processing. PLoS Biology 7, e1000019.

Robertson, E.M., Pascual-Leone, A., Press, D.Z., 2004. Awareness modifies the skill-learning benefits of sleep. Current Biology 14, 208-212.

Robertson, E.M., Press, D.Z., Pascual-Leone, A., 2005. Off-line learning and the primary motor cortex. J Neurosci 25, 6372-6378. 
Romano Bergstrom, J.C., Howard, J.H., Jr., Howard, D.V., 2011. Enhanced implicit sequence learning in collage-age video game players and musicians. Applied Cognitive Psychology. Romano, J.C., Howard, J.H., Howard, D.V., 2010. One-year retention of general and sequence-specific skills in a probabilistic, serial reaction time task. Memory 18, 427-441.

Römer, S., Schulz, A., Richter, S., Lass-Hennemann, J., Schächinger, H., 2011. Oral cortisol impairs implicit sequence learning. Psychopharmacology 215, 33-40.

Russeler, J., Rosler, F., 2000. Implicit and explicit learning of event sequences: Evidence for distinct coding of perceptual and motor representations. Acta Psychologica 104, 45-67.

Schendan, H., Searl, M., Melrose, R., Stern, C., 2003. An FMRI study of the role of the medial temporal lobe in implicit and explicit sequence learning. Neuron 37, 1013-1025.

Sefcsik, T., Nemeth, D., Janacsek, K., Hoffmann, I., Scialabba, J., Klivenyi, P., Ambrus, G.G., Haden, G., Vecsei, L., 2009. The role of the putamen in cognitive functions-A case study. Learning \& Perception 1, 215-227.

Shadmehr, R., Brashers-Krug, T., 1997. Functional stages in the formation of human longterm motor memory. Journal of Neuroscience 17, 409-419.

Shadmehr, R., Holcomb, H.H., 1997. Neural correlates of motor memory consolidation. Science 277, 821-825.

Siengsukon, C.F., Boyd, L.A., 2009a. Does Sleep Promote Motor Learning? Implications for Physical Rehabilitation. Physical Therapy 89, 370.

Siengsukon, C.F., Boyd, L.A., 2009b. Sleep to learn after stroke: implicit and explicit off-line motor learning. Neuroscience Letters 451, 1-5.

Song, S., 2009. Consciousness and the consolidation of motor learning. Behavioural Brain Research 196, 180-186.

Song, S., Howard, J.H., Jr., Howard, D.V., 2007. Sleep does not benefit probabilistic motor sequence learning. Journal of Neuroscience 27, 12475-12483. 
Song, S., Howard, J.H.J., Howard, D.V., 2008. Perceptual sequence learning in a serial reaction time task. Experimental Brain Research 189, 145-158.

Spencer, R.M., Gouw, A.M., Ivry, R.B., 2007. Age-related decline of sleep-dependent consolidation. Learn Mem 14, 480-484.

Spencer, R.M., Sunm, M., Ivry, R.B., 2006. Sleep-Dependent Consolidation of Contextual Learning. Current Biology 16, 1001-1005.

Squire, L.R., Knowlton, B.J., Musen, G., 1993. The structure and organization of memory. Annual Review of Psychology 44, 453-495.

Squire, L.R., Zola-Morgan, S., Cave, S.B., Haist, F., Musen, G., Suzuki, W.A., 1990. Memory: Organization of brain systems and cognition, Cold Spring Harbor symposia on quantitative biology. Cold Spring Harbor Laboratory Press, pp. 1007-1023.

Stickgold, R., Fosse, R., Walker, M.P., 2002. Linking brain and behavior in sleep-dependent learning and memory consolidation. Proc Natl Acad Sci U S A 99, 16519-16521.

Stickgold, R., Walker, M.P., 2005. Sleep and memory: the ongoing debate. Sleep 28, 12251227.

Uddén, J., Folia, V., Petersson, K.M., 2010. The Neuropharmacology of Implicit Learning. Current Neuropharmacology 8, 367-381.

Ullman, M.T., 2004. Contributions of memory circuits to language: The declarative/procedural model. Cognition 92, 231-270.

Walker, M.P., Brakefield, T., Hobson, J.A., Stickgold, R., 2003a. Dissociable stages of human memory consolidation and reconsolidation. Nature 425, 616-620.

Walker, M.P., Brakefield, T., Morgan, A., Hobson, J.A., Stickgold, R., 2002. Practice with sleep makes perfect: sleep-dependent motor skill learning. Neuron 35, 205-211.

Walker, M.P., Brakefield, T., Seidman, J., Morgan, A., Hobson, J.A., Stickgold, R., 2003b. Sleep and the time course of motor skill learning. Learn Mem 10, 275-284. 
Walker, M.P., Stickgold, R., 2004. Sleep-dependent learning and memory consolidation. Neuron 44, 121-133.

Weiermann, B., Cock, J., Meier, B., 2010. What matters in implicit task sequence learning: perceptual stimulus features, task sets, or correlated streams of information? Journal of Experimental Psychology: Learning, Memory, and Cognition 36, 1492.

Willingham, D.B., 1997. Systems of memory in the human brain. Neuron 18, 5-8.

Willingham, D.B., 1999. Implicit motor sequence learning is not purely perceptual. Memory and Cognition 27, 561-572.

Ziessler, M., Nattkemper, D., 2001. Learning of event sequences is based on response-effect learning: further evidence from a serial reaction task. Journal of Experimental Psychology. Learning, Memory, and Cognition 27, 595-613. 